\title{
Un carnaval inventado. El disfraz de lo Zoque en el Chiapas contemporáneo
}

Miguel Lisbona Guillén

Antropólogo e investigador de PROIMMSE-IIA, Universidad Nacional Autónoma de México.

Esta artículo tiene como finalidad reflexionar sobre una fiesta nacida en el año 2007, el Carnaval de Copoya, una localidad perteneciente al municipio de Tuxtla Gutiérrez, capital del estado de Chiapas (México). La carnestolenda no es una construcción reciente en el mundo, y tiempo habrá en estas páginas para profundizar en ello, pero sí llama la atención que en la localidad de Copoya, a escasos cinco kilómetros de la capital chiapaneca, surgiera una festividad cuando ya existía un carnaval celebrado conjuntamente por los que se reconocen como zoques en Copoya y en Tuxtla Gutiérrez.

De historiadores y antropólogos es conocido el pasado zoque del centro de Chiapas, y en concreto de su capital y de Copoya, lugar fundado en el siglo XIX por hablantes del idioma zoque como ha descrito con precisión Dolores Aramoni ${ }^{1}$. Hablantes de tal idioma todavía viven en los estados de Chiapas, Oaxaca, Tabasco y Veracruz, alejados de los grandes centros urbanos del país, cuya cercanía ha influido para que muchos lugares donde históricamente se habló el zoque hayan perdido de manera paulatina hablantes, como ha ocurrido en Copoya, donde ya casi no se hallan. La existencia de este idioma, del tronco lingüístico mixe-zoque-popoluca, tampoco es una exigencia identitaria, como rasgo cultural inamovible, para que los copoyeros o ciertos habitantes de Tuxtla Gutiérrez se asuman como zoques o, al menos, como descendientes de los mismos. Tampoco es de extrañar que lo zoque se encuentre presente en la capital en forma de apellidos, sabores alimenticios y en una serie de festividades que conforman un complejo entramado de cargos relacionados con devociones católicas, casi todas ellas uniendo a habitantes de Tuxtla Gutiérrez

1. Al respecto, Dolores Aramoni Calderón. Los refugios de lo sagrado. Religiosidad, conflicto y resistencia entre los zoques de Chiapas. México, CONACULTA. 1992. 
y Copoya, como han apuntado algunos estudios ${ }^{2}$ y también lo sigue haciendo de manera incansable la ya mencionada antropóloga Aramoni. El carnaval conjunto de Tuxtla Gutiérrez y Copoya es un ejemplo de dicha colaboración, aunque en la actualidad han aparecido versiones distintas de tal festividad en la capital chiapaneca y en Copoya.

Pero si la presencia de lo zoque está viva en el estado de Chiapas, tanto en los municipios donde prácticamente toda la población es hablante del idioma, y también de diversas formas en la capital chiapaneca y en la misma localidad de Copoya, ¿qué sentido tienen la invención de un carnaval cuando ya existía uno? De esta pregunta surgió la idea de escribir este texto, interrogante consciente de las suspicacias que puede conllevar, aunque no exenta de interés por seguir pensando las múltiples formas en que se nombre y utiliza lo zoque.

\section{La nueva visión de lo zoque}

Un aspecto que debe llevar al análisis antropológico es el tratamiento de lo étnico en los medios de comunicación, en muchos casos a través de referencias a las labores realizadas por instituciones culturales oficiales, las cuales suelen visualizar la diferencia cultural en lugares caracterizados por una pérdida paulatina o casi total del idioma indígena. Los hablantes de zoque son rara vez tomados en cuenta, y si lo son, forman parte de alguna actividad que los reúne con otros hablantes o exhablantes del mismo o de otro idioma, a manera de festival o encuentro. Estas modalidades de reunión han proliferado en los últimos años, y en el caso concreto de los zoques se visualiza a través del "Festival Cultural Zoque" y el "Festival de la Provincia Zoque", este último continuidad del anterior pero con distinto nombre; "El Día del Músico Tradicional Zoque", o el "Encuentro de Joyonaqueros" con motivo de las festividades del santo patrón de Tuxtla Gutiérrez, por citar sólo alguna de las modalidades ofrecidas con formato similar. Por supuesto, la carga organizativa corre a cargo de las instituciones encargadas en Chiapas de la divulgación cultural: el Consejo Estatal para las Culturas y las Artes (CONECULTA) y los ayuntamientos correspondientes, y por otras instancias a nivel nacional, como fue el caso del día del músico tradicional, donde participó la Comisión Nacional para el Desarrollo Indígena (CDI), sucesora del antiguo Instituto Nacional Indigenista (INI). Estas reuniones institucionalizadas no necesariamente son

2. Al respecto, Omar López Espinosa. Etnografía de las mayordomías de Tuxtla, Tesis de Licenciatura, UNACH, San Cristóbal de Las Casas. 2011. 
asumidas por los miembros de la Mayordomía del Rosario de Tuxtla Gutiérrez o por la Junta de Festejos de Copoya, que son los nombres que designan a las agrupaciones de personas encargadas de preservar las actividades festivas y religiosas de raigambre zoque. El deslinde de la mayoría de miembros de estas asociaciones, que resguardan la ritualidad zoque local de los actos ajenos a lo que consideran tradición, es un nítido posicionamiento frente a una visión folklorizante de las instituciones políticas y culturales de los gobiernos municipal y estatal.

Tal folklorización, por supuesto, condiciona de dos maneras las menciones a lo zoque. En primer lugar, se acerca al hecho diferencial cultural mediante el concepto de "rescate" del pasado o de la tradición y, en segundo lugar, ubica lo zoque como referencia identitaria de una localidad o un municipio. Un ejemplo ofrece mayor claridad a lo expuesto. La publicación de un "Calendario Zoque" en un periódico de la capital chiapaneca motivó las siguientes palabras: La historia proporciona los valores de identidad que definen las características más representativas dentro de la sociología y psicología de los pueblos [...]. Las raíces zoques que nos arraigan a esta tierra, llegan hasta nuestros días con su alegría y colorido, pero desconocidas para una cada vez más grande parcialidad de la población [...]. La importancia de reconocer en nuestro pasado las actividades que hasta el día de hoy nos dan identidad, da cabida a este calendario que debería formar parte de cada uno de los hogares tuxtlecos, con base al reconocimiento de nuestros orígenes, otorguemos a nuestra cotidianidad el valor intrínseco de la rica cultura que nos precede.

Ya habrá tiempo de tratar en estas páginas la conversión en espectáculo de lo festivo o ritual, pero no cabe duda que muchas de las actividades que tenían dichas características en la tierra de los zoques se están equiparando, con celeridad, a esta modalidad de espectáculo, por encima de la participación en los mismos. Fiestas antiguas o nuevas ocupan espacios físicos que anteriormente les eran ajenos o les estaban vedados. De esta manera el carnaval de Tuxtla Gutiérrez, todavía celebrado por personas que se reconocen zoques junto a sus conciudadanos de Copoya, tiene como núcleo de la celebración la danza de Napacpoetzé o Te'Hatajamaetzé, con una ritualidad alejada de los despliegues festivos de las instituciones políticas locales. Miembros de la Mayordomía del Rosario y de la Junta de Festejos de Copoya se han negado a participar en dichos actos por considerarlos folklóricos, aunque alguno de ellos, por decisión personal, y cobrando, se ha incorporado al melting pot de la carnestolenda capitalina oficializada. De ahí que en el año 2009 “danzantes 
de esta capital, así como invitados provenientes de lugares como Copainalá y San Fernando hicieron un despliegue de sus danzas al ritmo de tambor, carrizo, guitarra y armónica, en el escenario a cielo abierto en la Calzada de los Hombres Ilustres", lo que, a decir de un diario local, fue ejemplo "de las raíces que dan identidad al pueblo tuxtleco".

La novedad de esta forma de ubicar las expresiones culturales locales se adecua muy bien a la adhesión de otras innovaciones como lo son la proclamación de la "Embajadora del Traje Regional Zoque 2008" o, incluso, aspectos más políticos que adquieren legitimación a través de conceptos ya asimilados como tradicionales, por indígenas, como fue la elección, por primera vez, de un candidato a alcalde por un partido político a través de "usos y costumbres" en Tecpatán, municipio históricamente zoque.

Seguramente el caso más sintomático de esta reconducción de ciertas fiestas se observa en el Carnaval de Tuxtla Gutiérrez y en la invención de un Carnaval en Copoya, aunque dentro de este ciclo carnavalesco no habría que olvidar la promoción turística que el más conocido y estudiado de los carnavales zoques está recibiendo, el de Ocozocoautla ${ }^{3}$ (Rivera Farfán, 1991 y 1998; Loi, 2009). El tirón que los carnavales en forma de desfile tienen en el mundo, y en el país, ha promovido esta modalidad en la capital de Chiapas, aunque se quiera aderezar con referencias al pasado zoque, como se mencionó en párrafos anteriores.

La nueva celebración de Copoya reviste tintes distintos, puesto que resulta una invención al no haberse realizado en dicha localidad carnaval alguno en su historia. En el año 2007 un comité organizador, mismo que sigue llevando a cabo sus preparativos y puesta en escena hasta la actualidad (véase documento 1), estructuró una propuesta de festividad carnavalesca amparada por las instituciones culturales estatales y por el Ayuntamiento de la capital chiapaneca. No sólo se le apoya con invitaciones y publicidad a dicha manifestación festiva, sino que "el Gobierno manda la comida" que se ofrece a participantes y visitantes, como recordaba una de las cocineras en la celebración del año 2009.

La elección de una "reina zoque de la tercera edad", los bailables públicos y un desfile con carros alegóricos y manifestaciones musicales de diversa ín-

3. Al respecto, Carolina Rivera Farfán. "El Carnaval de Ocozocoautla", en Revista del Consejo Estatal de Fomento a la Investigación y Difusión de la Cultura 5: 27-32, nov-dic., Tuxtla Gutiérrez, Consejo Estatal de Fomento a la Investigación y Difusión de la Cultura. 1991. 
dole componen este carnaval que en gran número está integrado por alumnos de escuelas públicas dirigidos por sus profesores, y por músicos y danzantes del pueblo o de localidades vecinas. Rescatar las tradiciones y costumbres zoques se convierte en el argumento vertebrador para los organizadores y exégetas de esta festividad: "Estas celebraciones permiten mantener vivas las raíces que dan identidad a la población, además de dejar un legado a las próximas generaciones".

El carnaval conjunto de Tuxtla Gutiérrez y Copoya, en manos de los participantes en los cargos religiosos de la Mayordomía y de la Junta de Festejos de ambas localidades, y que no ha sido estudiado desde una perspectiva antropológica aunque Aramoni Calderón está trabajando como parte de todo el ciclo festivo anual de la capital chiapaneca desde hace varios años, cuenta ahora, por lo aquí expresado, con una competencia doble. Por una parte la suscitada por el carnaval copoyero y, por la otra, la ambivalente relación que el carnaval capitalino espectacularizado ofrece para alguno de los aspectos del pretérito carnaval, en concreto la ocasional contratación de danzantes y músicos.

Aunque este texto no pretende realizar un estudio del carnaval en sí, parece conveniente remitirse a sus orígenes para poder llegar a la concepción festiva que estas nuevas manifestaciones sugieren, a la vez que inquietan hacia la interrogación de sus transformaciones y nuevos caminos.

\section{De carnavales}

Historiadores y antropólogos han hecho del estudio del carnaval un tema perenne de las referencias festivas al pasado y al presente de pueblos y ciudades influidos por el cristianismo. De las clásicas aportaciones sobre el territorio hispano 4 pasando por trabajos que tienen al mundo indígena de los Altos de Chiapas como lugar de análisis ${ }^{5}$, el carnaval es punto nodal para interpretar el tiempo festivo. Es por ello que también muchas han sido las tentaciones a la hora de buscar en esta festividad sus orígenes remotos, paganos en el caso europeo, y simbolismos prehispánicos en el latinoamericano.

Esta especie de pasión por los orígenes no debe retraer que el carnaval era "un preludio lógico o [...] una antítesis previa", como recuerda Le Roy Ladurie ${ }^{6}$,

4. Al respecto, Julio Caro Baroja. El Carnaval. Madrid, Taurus. 1989.

5. Al respecto, Victoria Reifler Bricker. El Cristo indígena, el rey nativo. El sustrato histórico de la mitología del ritual de los mayas. México, FCE. 1989.

6. Al respecto, Emmanuel Le Roy Ladurie (1979) El carnaval de Romans. De la Candelaria al miércoles de Ceniza, 1579-1580. México, Instituto Mora. 1994. 
Lisbona Guillén, M. Un carnaval inventado. El disfraz de lo Zoque en Chiapas contemporáneo. Pág. 103-115.

a la purificación que representa la Cuaresma. Esta circunstancia real tampoco implica que su nacimiento y desarrollo no suscite diversas reflexiones inclinadas sobre su carácter urbano inicial ${ }^{7}$, las diferenciaciones entre las versiones urbanas y rurales ${ }^{8}$, o la unión entre fiesta carnavalesca y revuelta que tan bien expresó Le Roy Ladurie ${ }^{9}$ para la Europa moderna, y recuerda Delgado Ruiz ${ }^{10}$ para la urbanidad más próxima en el tiempo, por sólo citar algunas referencias.

Pero en la cuestión que nos ocupa - - y dejando posibles interpretaciones del contenido de los carnavales en tierras americanas, concretamente en poblaciones indígenas - , lo que parece ser un motor del nuevo carnaval de Copoya es la idea de continuidad con el pasado, algo que no debe sorprender y que ya fue utilizado para otros carnavales más conocidos, como lo recuerda Hobsbawm ${ }^{11}$ entre los brasileños.

La diversidad de expresiones festivas ligadas al carnaval en tierras chiapanecas, los múltiples elementos que la componen, así como el distanciamiento con prácticas existentes en la celebración del carnaval tuxtleco donde participan habitantes de Copoya, hacen que este nuevo carnaval pueda ser considerado una invención que toma como modelo la parafernalia urbana internacionalizada por los carnavales visibilizados en el siglo $\mathrm{XX}$ por los medios de comunicación. Por supuesto, este modelo de carnaval nada tiene que ver con la diversidad de enunciados rurales constatables en los pueblos de Chiapas y tampoco responde al modelo de carnavalización o de lo carnavalesco que popularizó Bajtin ${ }^{12}$ a la hora de ubicar la narración ahistórica y pluritonal $^{13}$, ejemplo de confrontación con la explicación unívoca y lineal de la realidad, y modelo de inversión del orden social.

No se está, pues, frente a la recreación de una antigua fiesta o al surgimiento espontáneo de una - a pesar de que se desconozcan los caminos por los que

7. Al respecto, Jacques Heers. Carnavales y fiestas de locos. Barcelona, Península. 1988. Pág. 256257

8. Al respecto, Josefina Roma, "Fiestas. Locus de la iniciación y de la identidad", en J. Prat y A. Martínez (Eds.), Ensayos de antropología cultural. Homenaje a Claudio Esteva-Fabregat, Ariel Antropología, Barcelona, 1996. Pág 204-214.

9. Op, cit., Le Roy Ladurie. 1994.

10. Al respecto, Manuel Delgado Ruiz. La festa a Catalunya, avui. Barcelona, Barcanova. 1992.

11. Al respecto, Eric Hobsbawm, "Proleg a l'edició catalana", en E. Hobsbawm y T. Ranger (Eds.), L'invent de la tradició, pp. 7-9, Barcelona, Eumo Editorial. 1988. Pág 7-9.

12. Al respecto, Mijail Bajtin, La cultura popular en la Edad Media y El Renacimiento. Madrid, Alianza Editorial.1994.

13. Al respecto, Manuel Delgado Ruíz. La festa a Catalunya, avui. Barcelona, Barcanova.1992. 
pueda transitar-, sino que su aparición se acerca más a fenómenos que diseminan lo étnico más allá de fronteras definidas, pero que responden, como bien lo ha expresado Galinier ${ }^{14}$, a las "búsquedas de raíces" o, si se prefiere, a modalidades de anclar en lo ancestral zoque la existencia de una identidad local, aunque se sostenga en un sustantivo generalizador como el utilizar la palabra "zoque".

Roberto DaMatta ${ }^{15}$, uno de los especialistas en los carnavales de su país, Brasil, lanzaba en una investigación considerada clásica una pregunta al aire: “cuando hablamos de carnavales y tenemos dos 'carnavales' en dos (o más) sociedades diferentes, ¿tenemos realmente un mismo fenómeno?”. La respuesta parece clara si se parte de una perspectiva que los estudie a través de su carácter festivo. En sus análisis sobre el desfile carnavalesco brasileño destaca su condición polisémica frente a otro tipo de desfiles, como el militar del día patrio, donde los símbolos, gestos y lenguas son marcadamente unívocos. De esta explicación de DaMatta, sin entrar en la complejidad del análisis carnavalesco, sería resaltable para nuestro caso esa diferenciación de fenómenos festivos que se esconden tras el nombre de carnaval y, por supuesto, la unicidad que el caso de Copoya representa dentro del panorama festivo local.

¿A dónde se quiere llegar con tal afirmación? En primer lugar, lo que se pretende realzar es que la adopción o visión de una realidad festiva estará ligada a un posicionamiento teórico determinado. La fiesta como transgresión del orden establecido, como crítica a la sociedad o al poder tan dado entre ciertos carnavales $^{16}$, significa una forma de observar la realidad que se contrapone a los análisis más afines a la sociología de Emile Durkheim preocupada por la misión renovadora de los vínculos solidarios de los miembros de una sociedad y por aquellos funcionalismos que la observarían como activadora de la cohesión social. Es decir, las afirmaciones de organizadores, participantes y medios de comunicación de este nuevo carnaval copoyero responden a dicho modelo cohesionador y pervivencial de la sociedad, o en este caso de la tradición zoque. La tarea - muchas veces olvidada - de quienes deberán estudiar estos fenómenos será ubicar esta nueva festividad en el universo simbólico, pero también político, en que se encuentra inscrita ${ }^{17}$.

14. Op, cit., Galinier. 2008. Pág. 111.

15. Al respecto, Roberto DaMatta, Carnavales, Malandros y Héroes. Hacia una sociología del dilema brasileño. México, FCE. 2002.

16. Al respecto, Burke, Peter. La cultura popular en la Europa moderna. Madrid, Alianza Editorial. 2005.

17. Op, cit., Delgado Ruíz. 1992. Pág. 14. 
Aunque para esclarecer con mayor nitidez estos aspectos hubiera sido necesario partir de una pregunta inicial: ¿este nuevo carnaval de Copoya es una fiesta? La división expresada por Jean Duvignaud ${ }^{18}$ para diferenciar fiestas de participación y fiestas de representación, y que es retomada por Rodríguez Becerra $^{19}$ (1982: 32) para castellanizar la clasificación en fiesta y espectáculo, sitúa este interrogante en una disyuntiva y enlaza perfectamente con otra tipología que divide la fiesta en dos modelos: "cuando la fiesta es un modelo de la realidad (es decir, cuando refleja con una relativa fidelidad la concepción cultural que una sociedad tiene de sí misma) y cuando la fiesta se presenta como un modelo para la realidad (o sea, cuando lo que se refleja a través de la fiesta no es tanto lo que la sociedad es o cree ser, sino lo que cree que debería ser o le gustaría ser $[\ldots]^{20}$

Si toda fiesta es un espectáculo es tema de discusión intrincado, pero a donde se quiere llegar con alguno de estos ejemplos teóricos es a complejizar los análisis futuros $\mathrm{y}$, sobre todo, a aportar dos aspectos que se pueden retomar desde ámbitos académicos al igual que por públicos lectores más amplios. El primero refiere a la utilización del pasado, y del pasado étnico en concreto, como soporte legitimador o nebulosa interpretativa. Legitimador porque la sola mención de lo zoque, para este caso en particular, no tiene trascendencia interpretativa alguna; por el contrario, disfraza tras el nombre la creación de un espectáculo, sin poner en duda su legitimidad por ello. Remueve, eso sí, la búsqueda de arraigo y las conciencias de una sociedad atravesada por una desigualdad secular que sólo parece alcanzar su tranquilidad a través del llamado cultural de los ancestros.

El segundo aspecto, ligado al anterior, se dirige al mismo contenido, organización y participación de este nuevo espectáculo, que en nada se diferencia de otros que otorgan al sustantivo étnico y su defensa su propia legitimación. Convertir en espectáculo lo étnico, por iniciativa de miembros de la sociedad civil o por instituciones gubernamentales, se ha vuelto un fenómeno cotidiano en el Chiapas y el México contemporáneo, aunque podría hacerse extensivo a otros lugares del planeta. Esta afirmación no tiene como objetivo realizar una crítica hueca sino que, por el contrario, enfoca los reflectores sobre realidades 18. Al respecto, Jean Duvignaud, "La Fète: essai de sociologie", Cultures, vol. III. París. 1976, (1): Pág. 13-25.

19. Al respecto, Salvador Rodríguez Becerra. "Métodos, técnicas y fuentes para el estudio de las fiestas tradicionales populares", en H. M. Velasco (Ed.), Tiempo de fiesta. Ensayos antropológicos sobre las fiestas en España, 1982. Ed. Tres-Catorce-Diecisiete, Madrid, Pág. 27-42.

20. Al respecto, Joan Prat. "Aspectos simbólicos de las fiestas", Tiempo de fiesta. Ensayos antropológicos sobre las fiestas en España, Ed. Tres-Catorce-Diecisiete. Madrid. 1982. Pág. 151-168. 
muy concretas. Una es el papel de las instituciones públicas, especialmente, a la hora de definir qué es y cómo debe comportarse lo étnico (lo zoque), cómo debe ser culturalmente en conclusión; la otra es la asunción por parte de determinadas personas, incluso de participantes en estas actividades espectacularizadas, de un discurso que homogeneiza lo étnico, trasladando los originales espacios de realización de fiestas y rituales a ámbitos higienizados, en una especie de folklorización de lo anteriormente vetado, o todavía denostado si no se incorpora a los mencionados ámbitos permitidos. El papel de la Iglesia católica en las denigraciones públicas de tales actividades ha sido permanente y, en el caso que nos ocupa, el control de las tres imágenes religiosas del templo de Copoya, y que conectan a dicha localidad con la capital del estado en una serie de visitas rituales, es el ejemplo más claro.

Esta forma de utilizar las actividades rituales o festivas, de crear alguna de ellas bajo el manto de la recuperación de tradiciones, es tan artificial como cualquier construcción identitaria; como afirma Delgado Ruiz ${ }^{21}$, todas las identidades son artificios construidos por nosotros mismos, y en nuestra modernidad esa parece ser una obligación constante: la de informar quién somos ${ }^{22}$. Las prácticas culturales, encabezadas por las manifestaciones festivas, se han convertido en hilos conductores de la identidad visible y nombrada, pero hay que recordar, a lo mejor como lo hizo Gellner ${ }^{23}$, que, sin la necesidad de identificación, las prácticas culturales siempre han sido como el propio aire que se respira.

\section{Congelar la realidad}

Como se habrá comprobado, uno de los hilos conductores que explican la creación de una nueva festividad, el Carnaval de Copoya, es la decisión de establecer, de "inventar una continuidad" con el pasado, tal como lo expresó Hobsbawm $^{24}$. Concretamente este autor, junto con Ranger, se encargó de recordar, además de delimitar teóricamente, lo que significaba una "tradición inventada", al mismo tiempo que ambos separaban lo que juzgaban era tradición y costumbre. La primera, incluyendo la inventada, tiene como característica la invariabilidad demostrada por la imposición de prácticas fijas y

\footnotetext{
21. Op, cit., Delgado Ruíz. 1992. Pág 119.

22. Op, cit., Delgado Ruiz, 2007. Pág195.

23. Al respecto, Ernest Gellner. Naciones y nacionalismo. México, CONACULTA y Alianza Editorial. Pág 87.

24. Al respecto, Eric Hobsbawm. "Proleg a l'edició catalana", en E. Hobsbawm y T. Ranger (Eds.), L’invent de la tradició., Barcelona, Eumo Editorial. 1988a. Pág. 7-9.
} 
normalmente formalizadas, mientras que la costumbre, en "sociedades tradicionales", tiene la función de "motor y engranaje" ya que no excluye el cambio ni la innovación sin perder los anclajes con el pasado ${ }^{25}$. En definitiva, sus reflexiones se dirigen a señalar cómo las tradiciones inventadas, tal como la comentada en estas páginas, "usan la historia como legitimadora de la acción y como cimiento de la cohesión del grupo".

Por tal motivo, no es extraño que quienes hayan estudiado el hecho festivo y su contenido tomen las reflexiones de Hobsbawm y Ranger para realizar afirmaciones en torno a las mismas: La fabricación de formalizaciones ritualizadas con look tradicional puede servir, entonces, para establecer o reforzar identidades simbólicamente deficitarias, pero también para cumplir idéntica misión en relación a instituciones o determinadas relaciones de poder o sistemas de autoridad, inculcando valores, convenciones, principios, creencias, etc. ${ }^{26}$

Es decir, al mostrar algo conocido, como la invención festiva del Carnaval de Copoya, lo que se quiere resaltar no es tanto su condición de tradición inventada, circunstancia fácticamente demostrable, sino su intención de ser un refuerzo identitario al mismo tiempo que se pliega a una concepción determinada de lo que debe ser lo zoque. Una fiesta "dirigida, reavivada o mantenida por las instituciones, a menudo decae y se convierte en una caricatura de sí misma" ${ }^{27}$.

Desconocer el carnaval ya existente realizado entre habitantes de Tuxtla Gutiérrez y Copoya mediante la creación de uno nuevo en esta última localidad, y bajo el amparo de las instituciones culturales, escenifica más que una preservación cultural, imposible por el dinamismo del hecho cultural en sí, una forma de fijar lo zoque gracias a su folklorización, e informa, a la vez, de un artificio identitario secundado por las instituciones políticas y culturales. No se está frente a un apuntalamiento de la identidad zoque de la capital de Chiapas o de su localidad emblemática por su origen poblacional zoqueano, sino que lo observado remite a una construcción claramente delimitada de lo que ha sido, es y debe ser lo zoque. Cuando hay que insistir en quiénes y cómo somos, lo que se está mostrando es un déficit identitario más que una recreación de tal identidad. Rara vez los hablantes de zoque con quienes se han 25. Op, cit..,Pág 22 .

26. Op, cit., Delgado Ruíz. La traducción del catalán es autoría del autor del presente artículo). 1992 Pág 121-122.

27. Op, cit., Roma. 1996. Pág 212. 
compartido rituales y fiestas remiten a dicha identidad zoqueana para justificar sus actividades, salvo cuando la presencia de miembros de instituciones culturales estatales así lo requiere. Lo zoque, incluso en su propia construcción idiomática, muestra muchas facetas, y la reseñada podría ser una más. La única diferencia, tal vez, es que en los últimos años la zoquedad referida a Tuxtla Gutiérrez y Copoya ha adquirido tintes de legitimación identitaria de un pasado compartido pero, sobre todo, de fijación a través de congelar lo que debe ser lo zoque. Y lo más significativo de lo hasta ahora narrado es que la Mayordomía del Rosario y la Junta de Festejos de Copoya siguen llevando a cabo sus actividades rituales sin necesidad de reflectores o afirmaciones innecesarias. Las manifestaciones culturales tienen muchas expresiones y no todas optan por el camino de convertirse en espectáculo.

\section{Referencias bibliográficas}

Aramoni Calderón, Dolores. Los refugios de lo sagrado. Religiosidad, conflicto y resistencia entre los zoques de Chiapas. México, CONACULTA. 1992.

Bajtin, Mijail. La cultura popular en la Edad Media y el Renacimiento. Madrid, Alianza Editorial. 1994.

Bricker, Victoria Reifler. El Cristo indígena, el rey nativo. El sustrato histórico de la mitología del ritual de los mayas. México, FCE. 1989.

Burke, Peter. La cultura popular en la Europa moderna. Madrid, Alianza Editorial. 2005.

Caro Baroja, Julio. El Carnaval. Madrid, Taurus. 1989.

DaMatta, Roberto. Carnavales, Malandros y Héroes. Hacia una sociología del dilema brasileño. México, FCE. 2002.

Delgado Ruiz, Manuel. La festa a Catalunya, avui. Barcelona, Barcanova. 1992. También "Tiempo de identidad. La representación festiva de la comunidad y sus ritmos", Fiestas, rituales e identidades 2004. Pág.77-98, R. Jimeno y J.I. Homobono (eds.) San Sebastián, Cuadernos de Antropología y Etnografía/Zainak, n. 26.También. Sociedades movedizas. Pasos hacia una antropología de las calles. Barcelona, Anagrama. 2007.

Duvignaud, Jean.“La Fète: essai de sociologie”, Cultures, vol. III (1): 13-25. París. 1976.

Galinier, Jacques "Indio de estado versus indio nacional en la Mesoamérica moderna", REVISTA DE MUSEOLOGÍA KÓOT, 2013, AÑO 3, No 4, ISSN 2078-0664, ISSNE 2307-3942 
Raíces en movimiento. Prácticas religiosas tradicionales en contextos translocales. Pág. 111-127, K. Argyriadis et al. (coords.). México, COLJAL, CEMCA, IRD, CIESAS e ITESO. 2008

Gellner, Ernest. Naciones y nacionalismo. México, CONACULTA y Alianza Editorial. 1991.

Heers, Jacques. Carnavales y fiestas de locos. Barcelona, Península. 1988.

Hobsbawm, Eric. "Proleg a l'edició catalana", en E. Hobsbawm y T. Ranger (Eds.), L'invent de la tradició, Pág. 7-9, Barcelona, Eumo Editorial. 1988. También,"Introducció”, L’invent de la tradición. Pág 13-25, E. Hobsbawm y T. Ranger (eds.). Barcelona, Eumo Editorial. 1988.

Le Roy Ladurie, Emmanuel El carnaval de Romans. De la Candelaria al miércoles de Ceniza, 1579-1580. México, Instituto Mora. 1994 (1979).

Lisbona Guillén, Miguel “¿Existe una cultura zoque? El concepto de cultura en el marco del debate contemporáneo", Presencia zoque. Una aproximación multidisciplinaria, Pág. 19-36, D. Aramoni, T.A. Lee y M. Lisbona (Coords.). México, UNICACH, UNACH, COCyTECH y UNAM, IIA, PROIMMSE. 2006.También, "Una indianitat aséptica: els zoques de la capital de Chiapas, Tuxtla Gutiérrez", Revista d'etnologia de Catalunya 33, Pág 8-17. Barcelona, Generalitat de Catalunya. 2008.

Loi, Manuela. El ciclo de carnaval en Ocozocoautla de Espinosa, Chiapas. Pastores, reyes, bufones y cohuinás, Tesis de Maestría en Antropología Social, UNAM, IIA y FFyL, México. 2009.

López Espinosa, Omar. Etnografía de las mayordomías de Tuxtla, Tesis de Licenciatura, UNACH, San Cristóbal de Las Casas. 2001.

Prat, Joan. "Aspectos simbólicos de las fiestas", Tiempo de fiesta. Ensayos antropológicos sobre las fiestas en España, Pág. 151-168, H. M. Velasco (ed.). Madrid, Ed. Tres-CatorceDiecisiete. 1982.

Rivera Farfán, Carolina. "El Carnaval de Ocozocoautla", en Revista del Consejo Estatal de Fomento a la Investigación y Difusión de la Cultura 5: 27-32, nov-dic., Tuxtla Gutiérrez, Consejo Estatal de Fomento a la Investigación y Difusión de la Cultura. 1991-1998 "La organización ceremonial en San Fernando y Ocozocoautla", en Cultura y etnicidad zoque, Pág. 117-128, D. Aramoni, T.A. Lee y M. Lisbona (coords.). Tuxtla Gutiérrez, UNICACH y UNACH. 
Rodríguez Becerra, Salvador. "Métodos, técnicas y fuentes para el estudio de las fiestas tradicionales populares”, en H. M. Velasco (Ed.), Tiempo de fiesta. Ensayos antropológicos sobre las fiestas en España, Ed. Tres-Catorce-Diecisiete, Madrid. 1982. Pág. 27-42.

Roma, Josefina. "Fiestas. Locus de la iniciación y de la identidad", en J. Prat y A. Martínez (Eds.), Ensayos de antropología cultural. Homenaje a Claudio Esteva-Fabregat, Ariel Antropología, Barcelona. 1996. Pág. 204-214. 


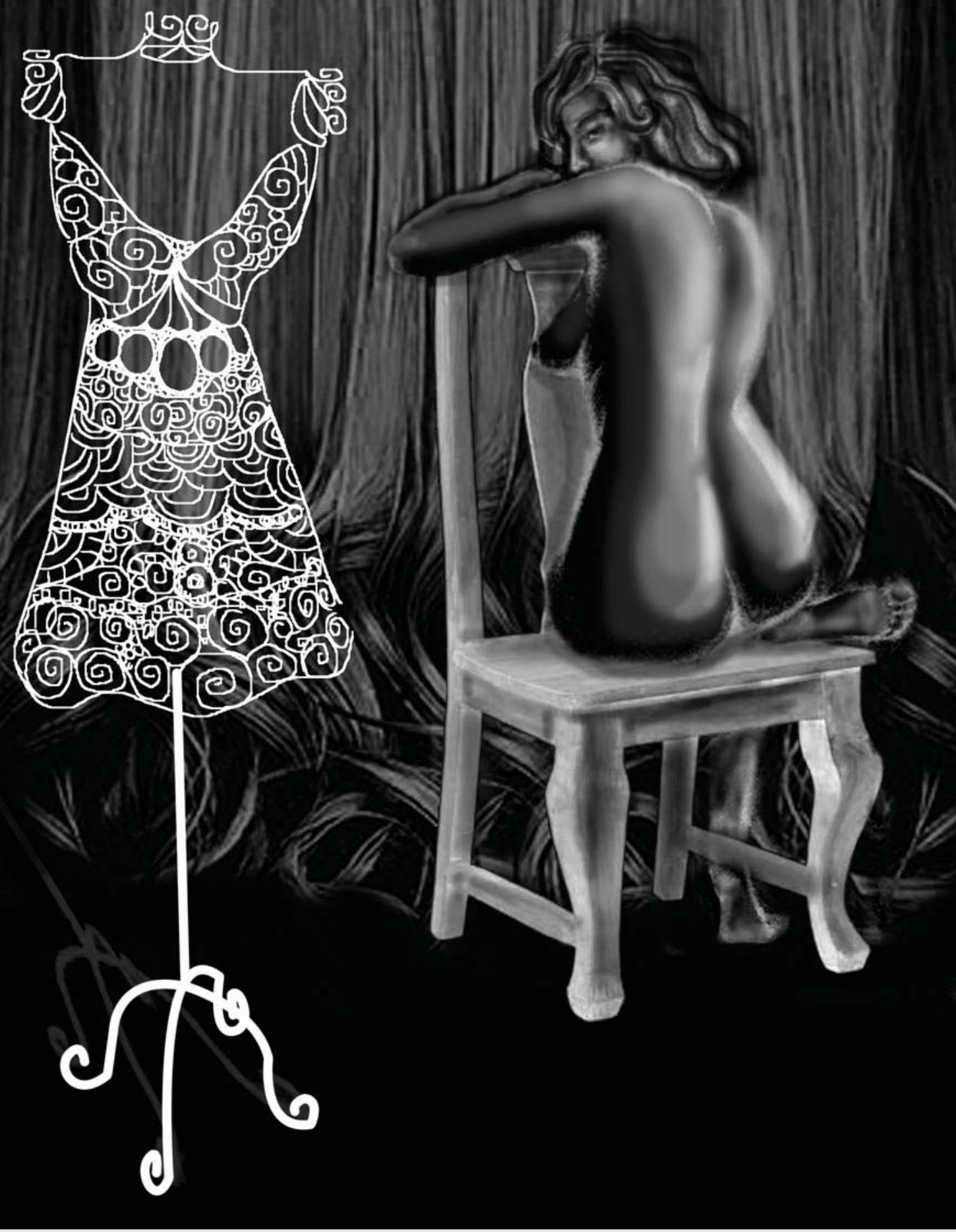

Imposición. Técnica mixta, 8.5" x 11". Rita Araujo. 2012. 